\title{
Study of the extracellular polymeric substances (EPS) in different types of membrane bioreactor (MBR) effluents
}

\author{
L. D. Chabalina, M. Rodríguez \& D. Prats \\ Water and Environmental Science Institute, University of Alicante, Spain
}

\begin{abstract}
One of the problems involved in operating membrane bioreactors (MBR) is membrane fouling. This is caused by the presence of wastewater constituents such as colloids, mineral particles, ionic components, micro-organisms and basically because of extracellular polymeric substances (EPS). EPS are highmolecular weight compounds secreted by microorganisms into their environment, and they are mostly composed of proteins and polysaccharides. An exhaustive study of EPS concentration is essential to improve MBR operation. In this paper, a comparative study of the most frequently used EPS extraction methods has been done: extraction using a cation exchange resin (CER) (Dowex $50 X 8)$, using formaldehyde $(36.5 \%)+\mathrm{NaOH} 1 \mathrm{M}$ and by heating. The best results were obtained when the CER was used, extracting in almost all experiments more than double the EPS extracted by the other two techniques. Additionally, determination of the optimum amount of CER required was carried out. The obtained value was $70 \mathrm{~g}$ CER/g VS. Afterwards, EPS determination of four different types of effluent using the same method was carried out. The wastewaters used were the following: a) young age sludge coming from an ice cream factory; mixed liquor from the municipal wastewater plant "Rincón de León", Alicante; mixed liquor obtained from the pilot membrane bioreactor of "Rincón de León", Alicante; mixed liquor obtained from a full scale MBR plant. Keywords: extracellular polymeric substances (EPS), EPS extraction method, membrane fouling, MBR effluent.
\end{abstract}

\section{Introduction}

The implementation of membrane bioreactor (MBR) in wastewater treatment offers many advantages over traditional activated sludge treatment. However, 
some problems have been detected in their operation, membrane fouling being the biggest one [1-3].

Wastewater constituents as colloids, mineral particles, ionic components, microorganisms and extracellular polymeric substances (EPS) are considered to be the most important foulants in membrane filtration processes [4]. EPS have been reported as being a major sludge floc component, causing a decline of permeation flux because of membrane fouling [5, 6].

EPS are a complex mixture of high molecular polymers excreted by microorganisms, products from lysis and hydrolysis, and organic matter adsorbed from wastewater [7]. EPS are mainly composed of carbohydrates and proteins, and in smaller quantities of humic substances, uronic and nucleic acids [8]. Many authors have defined two types of EPS: soluble and bound EPS [9, 10]. The first ones appear in the supernatant and the bound EPS occur as a capsule surrounding the bacteria cell wall [10].

For bound EPS extraction a lot of methods based on chemical, physical and physico-chemical processes have been described. Many authors have reported papers comparing the efficiency of extraction methods and the most important factors that determine good extractions [11-13].

The aim of this study is to compare the effectiveness of the three most used extraction methods: cation exchange resin (CER), formaldehyde $+\mathrm{NaOH}$ and heating. Some modifications of extraction techniques were done. Samples of activated sludges were taken from 4 four different treatment plants. The results are discussed in terms of the total EPS content (protein and carbohydrates) depending on the extraction method used.

\section{Materials and methods}

\subsection{Activated sludge samples}

Activated sludges from four different plants were used to carry out EPS extractions. Some of their main characteristics are shown in Table 1.

Table 1: $\quad$ Mean values of the main characteristics of sludge samples used.

\begin{tabular}{|l|c|c|c|c|}
\hline \multicolumn{1}{|c|}{ Parameters } & A & B & C & D \\
\hline Effluent treated & $\begin{array}{c}100 \% \text { industrial } \\
\text { sewage }\end{array}$ & $\begin{array}{c}100 \% \text { domestic } \\
\text { sewage }\end{array}$ & $\begin{array}{c}100 \% \text { domestic } \\
\text { sewage }\end{array}$ & $\begin{array}{c}90 \% \text { domestic, } \\
10 \% \text { industrial }\end{array}$ \\
\hline Sludge TS (g/L) & 4.42 & 3.13 & 6.73 & 8.23 \\
\hline Sludge VSS (g/L) & 3.77 & 1.74 & 5.6 & 5.85 \\
\hline HRT (hrs) & 85 & 56 & 83 & 71 \\
\hline SRT (days) & NA & 10 & 16 & 2.32 \\
\hline
\end{tabular}

NA: not available.

The sludges were denoted as follows: A) young age sludge coming from an ice cream factory; B) mixed liquor from the municipal wastewater plant "Rincón de León", Alicante; C) mixed liquor from the pilot membrane bioreactor of "Rincón de León", Alicante; D) mixed liquor obtained from a full scale MBR plant. 


\subsection{EPS extraction}

Three different slightly modified methods were used to extract bound EPS: (A) using a cation exchange resin (CER) Dowex 50x8, 20-50 mesh in the sodium form (Fluka 44445) [13], (B) using formaldehyde $(36.5 \%)+\mathrm{NaOH} 1 \mathrm{~N}$ [12], and (C) heating [14]. Those methods were selected because they are described the most in literature, but there is no standard procedure published.

Before extractions, sludges were centrifuged at $4000 \mathrm{~g}$ for 15 minutes at $4{ }^{\circ} \mathrm{C}$ using a SIGMA 4K10 centrifuge.

In method A, $150 \mathrm{ml}$ of sample was used and the sludge pellets were resuspended to their original volume using a buffer consisting of $2 \mathrm{mM} \mathrm{Na}_{3} \mathrm{PO}_{4}, 4$ $\mathrm{mM} \mathrm{NaH} \mathrm{PO}_{4}, 9 \mathrm{mM} \mathrm{NaCl}$ and $1 \mathrm{mM} \mathrm{KCl}$ at $\mathrm{pH} 7$ [13]. In methods $\mathrm{B}$ and $\mathrm{C} 50$ $\mathrm{ml}$ of sample was used and the re-suspension was done in a $\mathrm{NaCl}$ solution $(0.05 \%)$ to make the conductivity equal to that it had in the original sample.

The procedure of method A consisted in stirring the sludge with the CER for 16 hours at $900 \mathrm{rpm}$ [13]. The amount of CER was calculated using $70 \mathrm{~g} \mathrm{CER} / \mathrm{g}$ VSS (obtained from the work detailed in item 2.4). The extracted EPS were firstly separated from the CER/sludge by centrifugation $\left(4000 \mathrm{~g}, 4{ }^{\circ} \mathrm{C}, 1 \mathrm{~min}\right.$.), and then the supernatant was centrifuged (4000 g, $4{ }^{\circ} \mathrm{C}, 15 \mathrm{~min}$ ) in order to remove the remaining floc components.

Method B was based on a chemical process in which formaldehyde was added to the sludge and the mixture agitated for 1 hour at $900 \mathrm{rpm}$. Then a solution of $1 \mathrm{~N} \mathrm{NaOH}$ was added and the resulting mixture stirred at the same stirring intensity for 3 hours [12]. At last, centrifugation $\left(4000 \mathrm{~g}, 4{ }^{\circ} \mathrm{C}, 15 \mathrm{~min}\right)$ of the liquor was carried out

In method C, two types of EPS were separated: the loosely (LB) and the tightly bound EPS (TB). The first was extracted by adding the $\mathrm{NaCl}$ solution at $70{ }^{\circ} \mathrm{C}$ and mixing it for $1 \mathrm{~min}$ [14]. Then, the sludge was centrifuged at $4000 \mathrm{~g}, 4$ ${ }^{\circ} \mathrm{C}$, for $15 \mathrm{~min}$. The tightly bound EPS was extracted adding the $\mathrm{NaCl}$ solution at room temperature and was placed in a water bath at $60{ }^{\circ} \mathrm{C}$ for 30 minutes. Finally, the liquor was centrifuged as before. Figure 1 illustrates in detail the procedures for each extraction.

\subsection{Analytical methods used for EPS determination}

EPS determination was performed measuring the concentration of protein and carbohydrate by means of colorimetric methods. For the carbohydrate content determination, the phenol-sulphuric acid method of Dubois et al [15] was used. Glucose was used as standard. A Total Protein Kit (Sigma-Aldrich, TP 0330) based on Lowry's description [16], but modified by Peterson [17] was used to determine the protein content.

\subsection{Optimum amount of CER}

The optimum amount of CER required was studied using two types of wastewaters: $\mathrm{B}$ and $\mathrm{C}$, table 1 . The first sample was collected from the biological reactor of "Rincón de León" treatment plant, Alicante and the second one from 
the membrane bioreactor situated in the same place. The procedure consisted on adding 20, 40, 70, 100 and $120 \mathrm{~g} \mathrm{CER/g} \mathrm{VSS} \mathrm{to} \mathrm{the} \mathrm{sludge} \mathrm{following} \mathrm{the}$ instructions of method $\mathrm{A}$.

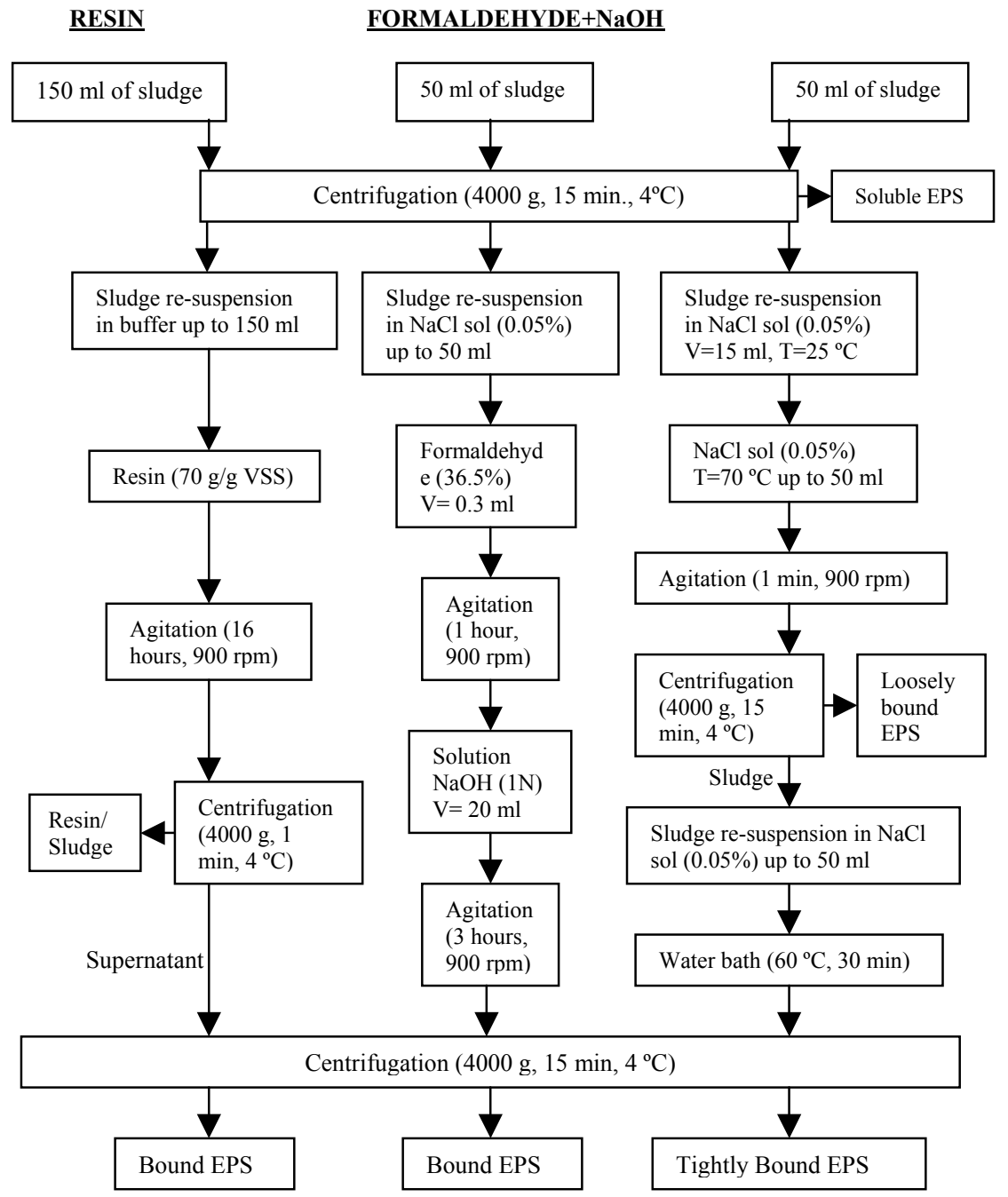

Figure 1: $\quad$ Procedures of EPS extraction methods.

\section{Results and discussion}

\subsection{Study of the optimum amount of CER for EPS extraction}

Results obtained from the study with varying amounts of CER for sludges B and $\mathrm{C}$ show dissimilar trends. In figure 2, the bar chart illustrates protein, 
carbohydrate and total EPS concentration for sludge B. Carbohydrate concentration rises slightly. However, protein concentrations show a substantial increase between 40 to $70 \mathrm{~g} \mathrm{CER/g} \mathrm{VSS}$. Evidently, the protein concentration trend controlled the total EPS concentration, obtaining a maximum value of $137.2 \mathrm{mg}$ of total EPS per each $\mathrm{g}$ of VSS when $70 \mathrm{~g}$ CER $/ \mathrm{g}$ VSS was used.

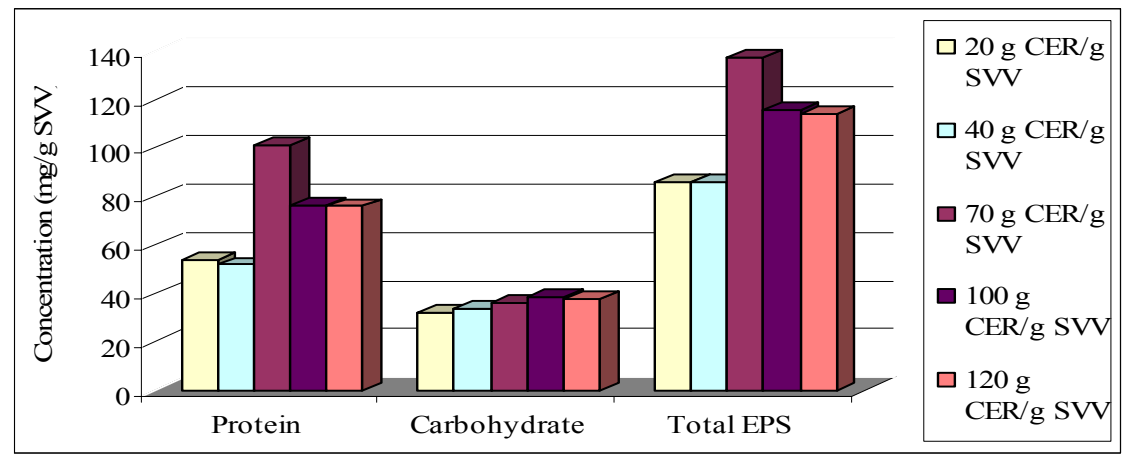

Figure 2: Total EPS extracted from sludge B using different CER amounts.

Regarding figure 3, which shows total EPS concentration for sludge C using different CER amounts, it is possible to see clearly that there is an increase as much in the protein as in the carbohydrate concentrations. As a result, total EPS concentration increased when additional quantities of CER were added. They ranged from 142 to $438 \mathrm{mg} / \mathrm{g}$ VSS for 20 and $120 \mathrm{~g}$ CER/g VSS respectively.

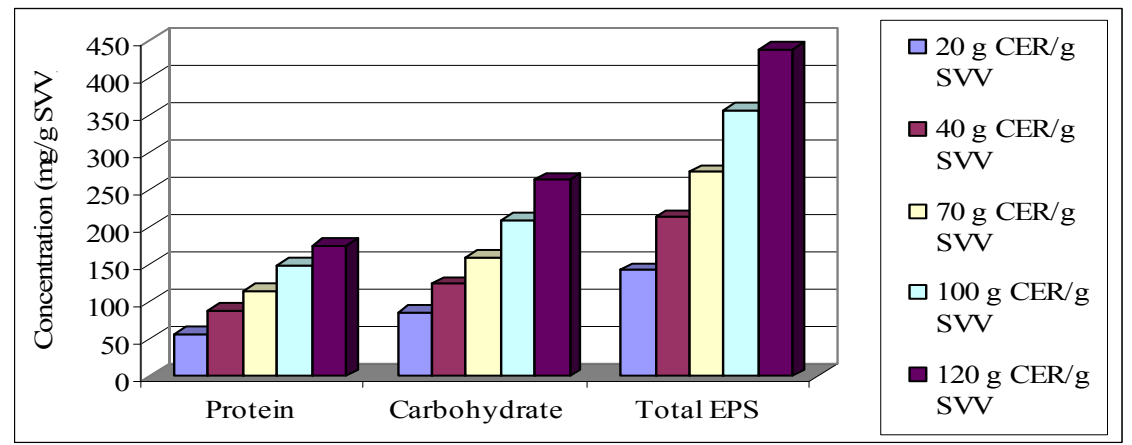

Figure 3: Total EPS extracted from sludge $\mathrm{C}$ using different CER amounts.

The behaviour of EPS extraction in the first assay could be explained by the fact that $70 \mathrm{~g} \mathrm{CER} / \mathrm{g}$ VSS was enough to extract all EPS contained in the sample, because the suspended solids (SS) concentration in it was low. In the second assay it was not possible to extract all EPS contained in the sample, probably because not sufficient amounts of CER were used, or due to the high SS 
concentrations. In the future, it is recommended to carry out a study diluting the sample to obtain lower SS concentrations.

\subsection{Analysis of EPS behaviour in the full scale MBR plant at different VSS concentrations}

For this study, sludge D was used to compare the three extraction methods mentioned (resin, formaldehyde $+\mathrm{NaOH}$ and heating) for 4 different concentrations of VSS. Samples for this test were collected punctually with at least 1 month of difference between sampling. Table 2 illustrates the EPS obtained at different concentrations of VSS for the three extraction methods studied.

Table 2: $\quad$ Total EPS at different VSS for the three extraction methods.

\begin{tabular}{|c|c|c|c|c|c|}
\hline \multicolumn{5}{|c|}{} & \multicolumn{5}{|c|}{ Total EPS (mg/l) } \\
\hline VSS $(\mathrm{g} / \mathrm{l})$ & Resin & $\begin{array}{c}\text { Formaldehyde } \\
+\mathrm{NaOH}\end{array}$ & $\begin{array}{c}\text { Heating } \\
\text { (LB EPS) }\end{array}$ & $\begin{array}{c}\text { Heating } \\
\text { (TB EPS) }\end{array}$ & $\begin{array}{c}\text { Heating } \\
\text { (Total EPS) }\end{array}$ \\
\hline 7.6 & 5512.0 & 3131.5 & 516.8 & 642.0 & 1158.8 \\
\hline 5.8 & 3169.5 & 1437.9 & 173.3 & 353.3 & 526.6 \\
\hline 5.33 & 735.7 & 857.3 & 26.2 & 255.3 & 281.5 \\
\hline 4.68 & 629.3 & 519.5 & 18.4 & 151.8 & 170.2 \\
\hline
\end{tabular}

As can be seen, total EPS extracted increased when VSS increased for all methods. This trend was clearly marked in the case of extractions with resin and formaldehyde $+\mathrm{NaOH}$. The maximum concentration values were 5512 and 3132 $\mathrm{mg} / \mathrm{l}$, and the lower ones were 629 and $520 \mathrm{mg} / \mathrm{l}$ for resin and formaldehyde $+\mathrm{NaOH}$ respectively. The difference between the maximum and minimum EPS released by heating was smaller: 1159 and $170 \mathrm{mg} / \mathrm{l}$ for 7.6 and $4.68 \mathrm{~g} / 1$ of VSS respectively.

Evidently, when the sludge had more suspended solids ( $>$ VSS), the amounts of EPS extracted were bigger. That seems to be the case because the production of EPS increases as the VSS concentration also increases. Furthermore, high SRTs enhance the slow growth of the bacterial population because there is more contact time with macro-molecules, which are used as substrate.

\subsection{Effectiveness of EPS extraction using the three methods studied}

Three different sludge samples (B, C and D) were used to extract EPS by means of the three before mentioned methods. Figure 4 illustrates that EPS concentration strongly depends on the extraction method. The effectiveness of the extraction decreased with the following trend: resin $>$ formaldehyde $+\mathrm{NaOH}$ $>$ heating. The latter was calculated as the sum of loosely and tightly bound ESP.

Resin extraction was more efficient for release of EPS than the other methods. CER extracts $1.4,1.2$ and 1.7 times more than formaldehyde $+\mathrm{NaOH}$ and 1.04 , 3.3 and 4.6 times more than the extraction by heating for sludge B, C and D respectively. 


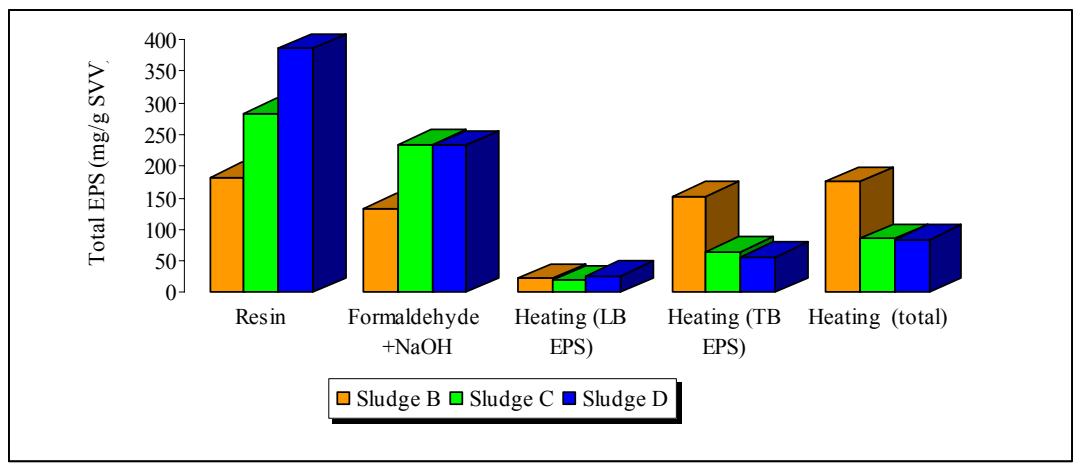

Figure 4: Amount of total EPS for the three sludge samples using the three extraction methods.

EPS content extracted by the resin method reached values from 182 to 386 mg per each gram of VSS. The results are in accordance with the literature and in the majority of the cases, our results were higher. Similar values were reported by Liu and Fang [18]: 6-254 mg EPS/g VSS; by Frolund and Palmgrem [13]: $127-432 \mathrm{mg}$ of EPS/g VSS. This method is very effective because it combines shear effects and chemical removal of bivalent cations, which allows easy release of EPS from flocs.

With respect to extraction using formaldehyde $+\mathrm{NaOH}$, we found values from 133 to $234 \mathrm{mg}$ EPS/g VSS. In contrast, there are studies that show better extractions with this method than with CER [11]. Comte and Guibaud [11] reported that EPS varied from 284-318 $\mathrm{mg}$ of EPS/g VSS to 21-23 $\mathrm{mg}$ of EPS/g VSS for formaldehyde $+\mathrm{NaOH}$ and resin respectively. This high extraction with formaldehyde could be explained by floc's dispersion mechanism principle [10], where formaldehyde fixes onto the cell avoiding cell lysis, and $\mathrm{NaOH}$ causes the dissociation of EPS acidic groups and repulsion between negatively charged EPS. As a result, greater release of EPS takes place. The low results obtained by Comte and Guibaud [11], when resin is used, could be related with extraction time. In this case, they reported only 1 hour for EPS extraction. Frolund and Palmgrem [13] have reported the consequences of short extraction times. They are used for mild extraction with minimum risk of cell lysis, however for an effective extraction at least 12 hours should be used.

Regarding the heating method, it can be said that the majority of experiments carried out by other authors consist of harsh extraction at $80{ }^{\circ} \mathrm{C}$ obtaining only tightly bound EPS [19]. Nevertheless, it is interesting to distinguish between the two types of EPS (LB and TB EPS), and this is possible using the method mentioned here. There are not many reports about this kind of double-extraction. In this paper, total EPS was 175,85 and $83 \mathrm{mg} / \mathrm{g}$ VSS and protein represented 80,63 and $81 \%$ of total EPS for sludges B, C and D respectively. Li and Yang [20] reported $40-56 \%$ of protein and $10-16 \%$ of carbohydrate because the rest were humic substances. It is not possible make a precise comparison because in 
our case, only protein and carbohydrate were determined. However, both papers show the lower concentration for carbohydrates and the higher concentration for proteins.

\subsection{Comparison of EPS concentrations for the four sludges studied}

This study was done to compare the behaviour of EPS concentrations of different types of sludges when extraction was carried out by the resin method. The amounts of protein, carbohydrates and soluble EPS obtained are showed in figure 5 .

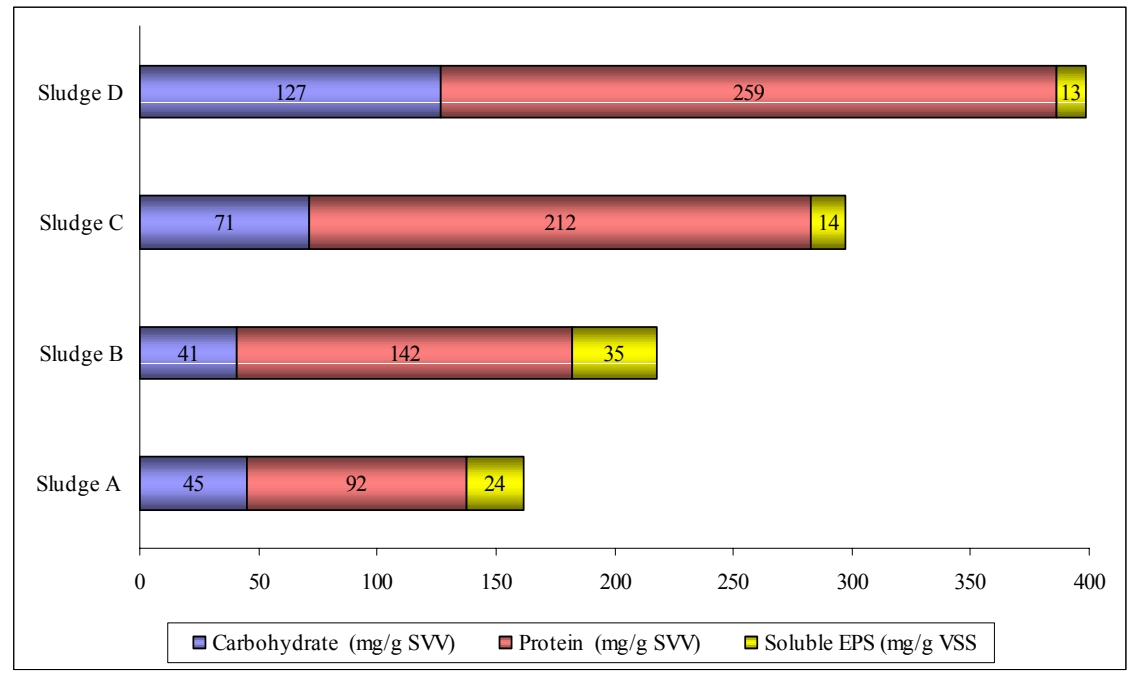

Figure 5: Amount of carbohydrate, protein and soluble EPS for the four sludge types using the CER method.

Protein in all cases appears as the major constituent of EPS representing the $67,78,65$ and $67 \%$ of the total EPS for sludges A, B, C and D respectively. In addition, this assay revealed a maximum value of $386 \mathrm{mg}$ EPS/g VSS for sludge $\mathrm{D}$, which has the highest SS concentration. Comte and Guibaud [11] reported concentrations of 301 and $322 \mathrm{mg} / \mathrm{g} \mathrm{VSS}$, less than those obtained by us. However, the soluble EPS reach 16 and $21 \mathrm{mg}$ EPS/g VSS, similar to those obtained in our study: 18, 19, 5 and $3 \mathrm{mg}$ EPS/g VSS for sludges A to D.

The ratios of protein/carbohydrate $(\mathrm{P} / \mathrm{C})$ obtained in this paper were 2.1, 3.5, 3 and 2 for sludges A to D. Similar values have been found by Comte and Guibaud [11]: between 1.6 and 2.6; Liu and Fang [12] found a value of 1.35. Our values were slightly higher than the others, which is in accordance with the protein concentrations reached. 


\section{Conclusions}

For sludges with low EPS content, $70 \mathrm{~g}$ CER/g VSS is sufficient to extract all the EPS in the sample. For high EPS content sludges, due to high VSS or high SRT, it was not possible to extract all the EPS.

Total EPS extracted increased when VSS increased for all extraction methods, more so in the case of extractions with resin and formaldehyde $+\mathrm{NaOH}$.

The effectiveness of the extraction decreased with the following trend: resin $>$ Formaldehyde $+\mathrm{NaOH}>$ heating. Resin extraction was $1.4,1.2$ and 1.7 times higher than with formaldehyde $+\mathrm{NaOH}$ and 1.04, 3.3 and 4.6 time higher than the extraction by heating for sludge $\mathrm{B}, \mathrm{C}$ and $\mathrm{D}$ respectively.

The major constituent of EPS in the four sludges studied was the protein with values higher than $65 \%$ of the total EPS. The ratios of protein/carbohydrate obtained varied from 3.5 to 2 .

\section{Acknowledgements}

This study was financially supported by the Conselleria de Empresa, Universidad y Ciencia from Generalitat valenciana (ref. ACOMP07/047), by the Ministry of Environment with the project "Treatment and wastewater reuse for a sustainable management" (CONSOLIDER) (ref. CSD200644), and by a grant from the University of Alicante to Liuba Dominguez Chabalina. The authors are grateful for the participation of EMARASA, SADYT, ESAMUR and the UTE Union Temporal de Empresa (URDEMASA-RED CONTROL) in the sampling task.

\section{References}

[1] Shane, R. \& Merlo, R., Influence of mixed liquor properties and aeration intensity on membrane fouling in a submerged membrane bioreactor at high mixed liquor suspended solids concentrations. Water Research, 41, pp. 947-958, 2007.

[2] Wang, X. \& Li, X., Membrane fouling in a submerged membrane bioreactor (SMBR): Characterisation of the sludge cake and its high filtration resistance. Separation and Purification Technology, 52, pp. 439445, 2007.

[3] Meng, F. \& Zhang, H., Identification of activated sludge properties affecting membrane fouling in submerged membrane bioreactors. Separation and Purification Technologies, 51, pp. 95-103, 2006.

[4] Nagaoka, H, \& Ueda, S., Influence of bacterial extracellular polymers on the membrane separation activated sludge process. Water Science and Technology, 34, pp. 165-172, 1996.

[5] Liang, S, \& Liu, C., Soluble products in membrane bioreactor operation: behaviours, characteristics and fouling potential. Water Research, 41, pp. 95-101, 2007.

[6] Rosenberg, S. \& Kraume, M., Filterability of activated sludge in membrane bioreactors. Desalination, 146, pp. 373-379, 2002. 
[7] Morgan, J. \& Forster, C., A comparative study of the nature of biopolymers extracted from anaerobic and activated sludges. Water Research, 24, pp. 743-750, 1990.

[8] Sponza, D., Extracellular polymeric substances and physicochemical properties of flocs in steady and unsteady-state activated sludge systems. Process biochemistry, 37, pp. 983-998, 2002.

[9] Higgins, M. \& Novak, J., Characterization of exocellular protein and its role in bioflocculation. Journal of Environmental Engineering, 123, pp. 479-485, 1997.

[10] Wingender, J., Neu, T. \& Flemming, H., Microbial extracellular polymeric substances: characterization, structure and function, Springer, pp. 1-13, 1999.

[11] Comte, S. \& Guibaud, G., Relation between extraction protocols for activated sludge extracellular polymeric substances (EPS) and EPS complexation properties. Part I: Comparison of the efficiency of eight EPS extractions methods. Enzyme and Microbial Technology, 38, pp. 237-245, 2006.

[12] Liu, H. \& Fang, H., Extraction of extracellular polymeric substances (EPS) of sludges. Journal of Biotechnology, 95, pp. 249-256, 2002.

[13] Frolund, B. \& Palmgrem, R., Extraction of extracellular polymers from activated sludge using a cation exchange resin. Water Research, 30(8), pp. 1749-1758, 1996.

[14] Li, X. \& Yang, S., Influence of loosely bound extracellular polymeric substances (EPS on the flocculation, sedimentation and dewaterability of activated sludge. Water Research, 41, pp. 1022-1030, 2007.

[15] Dubois, M \& Gilles, K., Colorimetric method for determination of sugars and related substances. Analytical Chemistry, 28, pp. 350-356.

[16] Lowry, O. \& Rosebrough, N., Protein measurement with the Folin phenol reagent. Journal of Biological Chemistry, 193, pp. 265-275, 1951.

[17] Peterson, G., A simplification of the protein assay method of Lowry et al. which is more generally applicable. Analytical. Biochemistry, 83(2), pp. 346-356, 1977.

[18] Liu, Y., \& Lam, M., Adsorption of heavy metals by EPS of activated sludge. Water Science and Technology, 43, pp. 59-66, 2001.

[19] Liu, Y., \& Fang, H., Influence of extracellular polymeric substances (EPS) on flocculation, settling and dewatering of activated sludge. Environmental Science and Technology, 33, pp. 237-273, 2001.

[20] Li, X., \& Yang, S., Influence of loosely bound extracellular polymeric substances (EPS) on the flocculation, sedimentation and dewaterability of activated sludge. Water Research, 41, pp. 1022-1030, 2007. 